\title{
Gender Dimensions in Disaster Risks Reduction Policy: Insights from Bangladesh
}

\author{
Sajal Roy, PhD \\ School of Social Sciences \\ Western Sydney University, NSW, Australia \\ E: Sajal.roy@westernsydney.edu.au; roysajal.wgs@gmail.com \\ Dr. Bishawjit Mallick \\ Marie Skłodowska-Curie Global Fellow \\ Chair of Environmental Development and Risk Management \\ Faculty of Environmental Sciences \\ Technische Universität Dresden / DRESDEN concept \\ 01062 Dresden, GERMANY \\ Utsab Bhattarai, PhD Candidate \\ Institute for Culture and Society \\ Western Sydney University, NSW, Australia \\ E: utsabbhattarai61@gmail.com
}

\begin{abstract}
This paper aims to delve into how gender dimensions observed before, during and after a disaster, have been addressed in two internationally recognised frameworks developed for reducing risks of disasters: Hyogo Framework Action (2005-2015) and Sendai Framework for Disaster Risk Reduction (20152030). Building on a systematic review, we evaluate 15 scholarly peer-reviewed journal articles, including book chapters and websites in areas of gender, disaster risk reduction and vulnerability. This study documents a comparative picture of these two frameworks and shows the practical implications of the Sendai Framework for Disaster Risk Reduction (SFDRR) by addressing women's empowerment in the light of their active participation in disaster risk reduction process. The findings of the study suggest that the frameworks have discussed the reduction of women's socioeconomic vulnerabilities, as well as encouraged their empowerment. Comparing the two frameworks, it appears in the current study that there has been a significant gap in the existing literature that does not explicitly document comparing and contrasting features of a gender lens in the policy documents.
\end{abstract}

Keywords: Disaster, Vulnerability, Women, Gender, Disaster Risk Reduction, Bangladesh

\section{Introduction: an overview on gender, disaster and vulnerabilities}

The frequency and intensity of climate-induced disasters are increasing in Bangladesh. Due to the lack of access to services and resources, the minority are disadvantaged. Women and 
adolescents are considered as 'vulnerable within the vulnerable' because of their socioeconomic conditions and poor living standards (Ariyabandu, 2009). In post-disaster situation, women including the ethnic teenage girls staying in a temporary shelter hardly use the toilet facility without basic privacy and sanitary products in Bangladesh (Kabir et al., 2016). Therefore, they suffer from health-related vulnerabilities. In 2005, almost 168 countries adopted the Hyogo Framework of Action (HFA) in order to achieve sustainable reduction of disaster losses to prevent human lives as well as social, economic and environmental assets of individuals, communities and nations (UNISDR, 2014). Inspired by the success of the HFA in the South-Asia region, the SAARC (South Asian Regional Cooperation) Disaster Management Centre (SDMC) was established in 2007 in New Delhi. Its aim was to create a comprehensive regional framework on disaster management. The aims are to enhance the multi-hazard risk management approaches by sharing early warning, training, research findings and documentation (Childs, 2013).

The renewed commitment following the HFA regarding Disaster Risk Reduction (DRR) is the Sendai Framework of Actions (SFDRR) (2015-2030). It considers the lessons learned from the implementation of HFA. The primary objective of the Sendai Framework of Disaster Risk Reduction is to substantially lessen the disaster risk, particularly the losses human casualties, livelihoods and health. In the same way as the HFA, the SFDRR includes a "peoplecentred" approach to reduce disaster induced exposures. In addition, it includes wellengagement and partnership with "society" to provide individual attention to a group of people that are disproportionately affected by disaster, such as the poorest (UNISDR, 2015). In SFDRR, the expertise and experiences collected through community discussion, traditional knowledge, science and technology have gained priority of action. For example, while the HFA has mentioned 'science' for nine times, the Sendai has articulated it for 21 times (Poterie et al., 2015). This trend represents an increased focus on science and technology at global scales as a solution to significant problems created by disaster and climate change (Baudoin, 2014). Since 2015 to date, the national governments of UN state members have implemented post-2015 Sustainable Development Goals (SDG) and the Paris Agreement on climate change. Ten of the seventeen SDGs are related to the need for disaster risks reduction as mentioned in the 2030 Agenda for Sustainable Development. The Paris Agreement also aims to hold the global average temperature below $2^{\circ} \mathrm{C}$ per industrial level to provide efforts with the objective of "significant reduction of risks and impacts of climate change" (Ki-moon, 2016). 
The 2015 international agreements (such as Paris Agreement and Sustainable Development Goals) promoted gender equality and human rights to build the resilience of vulnerable and marginalised group of people in the communities (Drolet et al., 2015). However, it is inevitable to create a gender-equitable, inclusive and sustainable future for the development of all the UN member states that are vulnerable to climate change. For example, during the recovery period, longstanding biases against women can be challenged by programmes that are sensitive to their needs and entail equal partners in recovery work (UNISDR, 2003). It was highly context-relevant in countries (such as Bangladesh, India and Nepal) affected by extreme weather events. The South-western coastal Bangladesh ${ }^{1}$ was hit by tropical cyclones $-\mathrm{Sidr}$ (2006), Aila (2009), Mohasen (2013), Titly (2019), Mora (2019) - hit on the southwest coastal regions of Bangladesh ${ }^{2}$. Soon after Cyclone Mohasen, the involvement of both men and women increased within the area of decision- making for disaster management and climate change adaptation to abate their loss and damage (Samira, 2013).

Gender, as a cross-cutting phenomenon, is intricately connected to disaster risk reduction planning and implementation. The HFA and Sendai Frameworks potentially encourages women's participation in the planning and implementing guidelines for disaster risk reduction. For building community resilience, a gender dimension has to be 'integrated into all disaster risk management policies, plans and decision-making processes, including those related to risk assessment, early warning, information management and education and training ${ }^{2}$. Traditionally, women are the primary caretakers of the family in the disaster-affected rural areas in Bangladesh. Post-disaster, rural women utilise physical labour for rebuilding houses, reconstructing sheds and rehabilitating livestock. The study of Garai (2017) reveals increased participation of women in agricultural activities in post-disaster context. In Muslim societies, certain cultural norms such as the wearing of a sari (a female cloth) obstructs women from making easy physical movement while seeking a cyclone shelter. Inside the shelter, female disaster-survivors undergo gender-based violence such as physical torture that includes beating, slapping and being touched by men in the relief queue (Rezwana \& Pain, 2020). More than $70 \%$ of women have experienced gender-based violence in crisis settings by becoming the prey of the male disaster survivors (Drolet et al., 2015). According to UN Women, 60\% of preventable women mortality deaths take place because of conflict, displacement and natural disaster. During an extreme event, women died more than seven times compared to men, and

\footnotetext{
${ }^{1}$ Source: https://www.ncbi.nlm.nih.gov/pmc/articles/PMC5580535/, accessed 15 November 2019.
} 
women are mere recipients of limited basic needs provided by aid and relief agencies (Drolet et al., 2015). As analysed by Ginige, Amaratunga and Haigh (2009), the practical demands and concerns of women need to be incorporated into disaster risk reduction plans and strategies so that they are considered both as beneficiaries and decision-makers. Given this broader context of gender differentiated impacts of climate-induced disaster, the current research investigates the ways in which gendered dimensions have been addressed in the HFA and SFDRR frameworks.

\section{Method and materials}

This section details the application of the method to meet the aim of this study. According to Smith et al. (2011), systematic reviews explicitly explain the purpose of the review, selection of sources and analysis of sources in the research process. In addition, systematic reviews find out several research works suited to the specific research questions and explicitly identify related literatures of such indicators (Moller et al., 2016). For reviewers, systematic reviews assist to compare and summarise sources, aligned with the key objective of the research study. Conducting a systematic review requires consideration of sources, review selection, quality assessment of reviews, presentation of results and implications for practice and research. Detecting and navigating relevant literature associated with policies associated with gender and disaster risk reduction, specifically for Bangladesh, is a daunting task, yet crucial to the success of a systematic review that is utilised in this study. The material sourced provides the information from which evidence, conclusions and recommendations are drawn (Smith et al., 2011). However, establishing a systematic search strategy, before commencing the literature search, is fundamental to appropriate and successful information retrieval. This planning assists in meeting the requirements of the systematic review and in answering the research question. In developing a search strategy, the scope of the search, its diligence and the time available to conduct it, all need to be considered. The aim is to ensure that the systematic review of reviews is comprehensive, thorough and objective (Smith et al., 2011).

Following Moller and Myles (2016) and Smith et al. (2011), this study utilises a systematic review of 15 peer-reviewed journal articles (2009-2020) regarding the current practices and evidence of gender dynamics, socio-economic vulnerabilities and the global disaster risk reduction frameworks. The indicators of selecting the literature reviews were based on the relevance of disaster risk, women empowerment, vulnerabilities and also the globally accepted policies on DRR planning and implementation. Peer-reviewed journal 
articles were identified through the google search engine following a systematic search with the keywords: Disaster, Vulnerability, Women, Gender, Disaster Risk Reduction, Bangladesh. From the findings based on prominence and significance related to disaster risks reduction, two policy frameworks were systematically analysed. Firstly, the Hyogo Framework of Action 2005-2015, the blueprint of disaster risk reduction frameworks. Secondly, the recent Sendai Framework for Disaster Risk Reduction 2015-2030 as a successful instrument of the HFA. It is a 15-year non-binding voluntary agreement that outlined seven targets and four priorities of actions for disaster risk reduction. The global 2030 Agenda for Sustainable Development Goals (SDGs) has also been reviewed for analysing the components of disaster risk reduction among the 17 goals. Additionally, the Paris Agreement (2015) has also been reviewed as one of the most vital documents in tackling climate change, and has been ratified by 185 countries to hold the global temperature below $2^{\circ} \mathrm{C}$. Thus, the study establishes a comparison between the HFA and Sendai frameworks to highlight the gaps and prospects of the policy outlines. Furthermore, an analytical framework is proposed for helping out affected women to break through the traditional notion of cultural barriers and enhance resilience.

\section{Results: Gendered dimensions of policy documents in disaster risk reduction}

In this section, we argue the ways in which gendered dimensions have been addressed in the HFA and SFDRR frameworks for reducing disaster risks and building resilience, postdisaster.

\section{HFA Assessment}

The Hyogo Framework of Action 2005-2015 is the most important international document popularising the notion of DRR. The timeline of 2000-2009 is the critical decade for shifting concern around disaster issues, with an increased focus on risk preparedness. From 2005 to 2015, this framework was adopted, aiming to reduce the number of deaths and mitigate socioeconomic and environmental asset losses of the affected communities and countries (UNISDR, 2015). In this framework, three strategic goals and five priorities for action are set to be achieved. One strategic goal is to focus highly on the issues related to disaster prevention, mitigation, preparedness and reduction of vulnerabilities by employing policies, planning and programming entirely for sustainable development. The HFA, global blueprint of DRR, emphasised the importance of gender by calling it 'integrated into all disaster risk management policies, plans and decision-making processes, including those related to risk 
assessment, early warning, information management and education and training' ${ }^{3}$ (UNISDR, 2015). After developing the HFA over the last ten years, it has proven that women and girls possess the skills and capacity to prepare for, respond to and recover from crisis, and to manage risk and build resilience (Wahlström, 2012).

Although this framework highlights vulnerability reduction, it ignores the causes of vulnerability, which are essential factors for reducing disaster risk. Moreover, an inadequate number of institutions and lack of mechanisms and capacities at all levels (particularly at the community level) systematically contribute to hazards. The underlying conditions and causes of social vulnerability are not yet adequately addressed in other policy or practice (Lisa et al., 2016). If the root causes of vulnerability are appropriately treated, people will be able to take steps accordingly based on vulnerability identification and assessment results. Different formal and informal laws such as the Disaster Management Act 2012, National Policy on Disaster Management 2009, and the Standing Orders on Disaster 2019. These are developed and applied considering cultural practice and attitudes contributing to reducing disaster risk. For example, flexible approaches to receiving new technology helps to reduce disaster loss. On the other hand, strong mental stigma increases the chance of increased exposure to a disaster. Most literature discussed requirements of addressing gender norms, roles and relations in institutional processes to ensure equitable participation and benefits (WHO, 2013). Still, they hardly respond to the needs of those norms created. The technical supports of shelter, water and sanitation can be delivered by professional staffs and planners (Drolet et al., 2015).

Emphasizing preparedness and vulnerability reduction, HFA framework also gives importance to disaster adaptation. For example, discussing the decline of underlying risk factors, it states "Promote the integration of risk reduction associated with existing climate variability and future climate change into strategies for the reduction of disaster risk and adaptation to climate change". It is vital to mention that DRR covers risk reduction, whereas adaptation encompasses the process of adjustment.

\section{Sendai assessment}

The Sendai Framework for Disaster Risk Reduction 2015-2030 was adopted at the Third UN World Conference in Sendai, Japan, on March 18, 2015. It is the outcome of stakeholder consultations initiated in March 2012 and inter-governmental negotiations from July 2014 to

\footnotetext{
${ }^{3}$ Source: https://www.unisdr.org/files/1037 hyogoframeworkforactionenglish.pdf, accessed 26 April 2020.
} 
March 2015, supported by the United Nations Office for Disaster Risk Reduction. It is a voluntary and non-binding agreement taken for fifteen years, in which it is stated that every country has a responsibility to work on disaster risk reduction schemes. The framework focuses on capacity building and coordination of local government with private sectors and other stakeholders to ensure effective implementation of DRR activities. This framework also incorporates the practices of indigenous people dealing with natural disasters, as it can contribute to the development and implementation of plans and mechanisms. It articulates the need for understanding disaster risks, vulnerability and hazard characteristics; strengthening risk governance; accountability for disaster risk management; preparedness to reduce vulnerabilities; and recognition of stakeholders and their roles.

The Sendai Framework sets seven explicit goals with a view to following the progress of existing framework in preventing, preparing, and reducing natural disaster. One of the objectives of this framework is to lower the disaster-caused mortality rate globally by 2030 compared to the period of 2005-2015. For this reason, the Sendai Framework is considered as a comprehensive framework compared to the Hyogo Framework (UNISDR, 2015). Furthermore, the HFA consists of strategies such as resilience strategy, emergency response strategy, and emergency livelihood response program to help raise awareness of the concerned people and institutions. This also helps stakeholders, national governments, international aid agencies, regional community, and so on to make the political commitment to focus and catalyse actions at all levels. However, more integrated efforts are needed to tackle the underlying disaster risk drivers such as poverty, gender discrimination, rapid urbanization, climate change, demographic change and non-disaster risk-informed policies (PreventionWeb, 2017).

Although the Sendai Framework emphasises the responsibility of community people on reducing disaster risk, it has not explained how it can be implemented (UNISDR, 2015). SFDRR has promoted local strategies used to reduce vulnerabilities, as well as the funding opportunity that should be provided directly to those communities so that they can foster adaptive capacity building and strengthen local leadership (Kuruppu \& Willie, 2015). The absence of adequate critical infrastructural and institutional support from the individual to the community level is a significant issue of disaster management. The critical infrastructure includes water supply, electric power supply, road and transportation and gas supply system, 
whereas institutional support indicates government legislative support, non-government structural and non-structural support.

Natural and socio-economic characteristics of a region are also responsible for enhancing the vulnerability of its inhabitants. Planners, investors, politicians and people in the community must agree on this common ground to bring about significant infrastructural development in the respective locality (Mallick, Ahmed and Mallick, 2017). Sendai Framework has stressed the practical implementation of gender-sensitive policies, plans and programs regarding the reduction of disaster-risk so that women can be empowered for predisaster preparation by implementing formulated plans and strategies. This gender-sensitive empowerment will build their capacity to secure alternative means of livelihood in maintaining the post-disaster situation (UNISDR, 2015).

SFDRR does not guide to ensure preparedness and participation of women inthe disaster risk reduction process for developing countries like Bangladesh, where women are considered as subordinate to men. During the disaster, many women and children are caught inside their homes, while men are out of their homestead. Women and girls are physically weak because of nutritional deficiencies caused by lack of access to nutritious food, also increasing their physical weakness. They become mentally weak and sick because of social stigma and superstitions. Moreover, it does not articulate how women can secure their means of livelihood in the post-disaster phase in male-dominated societies. von Meding et al. (2016) out that women in many countries like Bangladesh cannot be present in public spheres without male accompaniment, and their limited access to public spaces reduces their chance of obtaining useful information in times of emergency. In this situation, the question arises of how women's means of livelihood will be secured without the help of men.

\section{Gender perspective on disaster risk reductions: before, during and after disaster}

Understanding how gender relations shape women's and men's lives are critical to Disaster Risk Reduction (DRR). Participation of both men and women will ensure gender equity and empowerment in this process. Women's and men's different roles, responsibilities, and access to resources influence how each will be affected by various hazards, and how they will cope with and recover from a disaster. Unequal power relations between women and men mean that, despite the incredible resilience and capacity for survival that women often exhibit in the face of a disaster, they also experience a range of gender-specific vulnerabilities. Notwithstanding, 
the vulnerability of women is always consistent in three phases: the pre-disaster period, at time of disaster and post-disaster situation.

\section{Vulnerability before disaster}

Experience of vulnerabilities to disaster differs from women to men, because the context of vulnerability depends on existing physical, economic and social capacity that shape the social context to expose a person to disaster. In particular, women are the most vulnerable and worst sufferers of a society not only at the time of the disaster, but also before the disaster (Islam, 2012). Women's decisions regarding family planning, family budget and social institutions are not prioritized in the family. Even in severe cases, their choice is ignored. For example, in Nepal, women are not allowed to leave their house without the permission of men; this social norm adds to their vulnerability by delaying their escape attempts during a disaster (von Meding et al. (2016).

Women in Bangladesh follow the rules and customs of society because of patriarchal norms. For example, in Muslim communities, cloths (cloak or veil, saris and garments) worn by women often limit their mobility in surviving an emergency. Therefore, social and cultural constraints need to be addressed in the warning system of disaster. As women delay taking shelter in the haven, this increases their vulnerabilities. For example, in many Muslim conservative families, women are not even allowed to seek shelter before a male. In this situation, the participation of women in the discussion of plan and policies regarding disaster risk reduction is restricted (Alidou, 2013). As a result, they (women) miss important information about disaster preparedness, early warning, awareness signals etc. Thus, the lack of knowledge about disaster preparedness keeps them away from taking preparation for any upcoming disaster. Therefore, defying social constraints will be a difficult task to empower women or to make them community level decision-makers (Drolet et al., 2015) because of lack of participation and relevant knowledge about the disaster. Further instances pointed out that women wait to take decisions from their husbands (Kabir et al., 2016). During Sidr and Aila in Bangladesh, the warning was aired but unavailable to many women, and in consequence, no evacuation occurred causing danger during the cyclones.

\section{Vulnerability during disaster}

Women and girls experience hard hits from disaster globally, but men and boys do not (von Meding et al., 2016). Kabir et al. (2016) exemplified that mothers often had to lay down their 
lives during a cyclone while trying to save their offspring because it was not comfortable enough to quickly take them to shelter houses (Mallick, Ahmed, and Mallick, 2017). Women sometimes had to face social and cultural restrictions, religious rules and regulations, social superstitions etc. that restricted them from taking refuge in cyclone shelters. Moreover, since women are responsible for taking care of family members and resources, they are sometimes the last member of the family to leave the house to seek distant shelters, even after getting warnings long before (Mallick, Ahmed, and Mallick, 2017). For example, during Sidr, a husband left his wife when her hair entangled with a tree at the time of seeking safe shelter.

During a disaster, women are often reluctant to go to shelter homes due to several reasons. Women are discouraged from taking refuge in the shelters because there is a lack of facilities needed for them. The facilities absent are separate space, separate toilets, lights and fresh potable water. For example, Muslim families of the coastal areas are concerned with the lack of having separate space and washrooms. Many women of these families maintain the strict custom of purdah (cloak). For this reason, they do not like to expose themselves to strangers (Saha and James, 2016). Lack of washrooms is a severe problem in a shelter house. Lack of lavatories made women bound to defecate in the open place; otherwise, they had to retain until night or early hours of the morning. Moreover, it was very difficult for pregnant women who were due to give birth. Besides this, sufferings of women were exasperated because they were forced to stay in small shabby overcrowded rooms and had to take care of their children (Drolet et al., 2015).

\section{Vulnerability after disaster}

In the post-disaster situation, an additional set of vulnerabilities for women is created. Responsibility is shouldered upon women to rebuild lives and maintain the children while husbands or sons are away, earning a livelihood. Moreover, in female-headed households (after losing their husbands), women become the sole breadwinners of the family. In these situations, food insecurity of women and girls increases their suffering, because the scarcity of food rises during the post-disaster phase. In addition to food insecurity, child marriage and human trafficking result in the dropout of female students from school (Drolet et al., 2015). Pregnant women go through mental and physical trauma, sometimes causing the birth of physically challenged children. In a post-disaster situation, children and older adults may go through many physical vulnerabilities. Notably, many separation cases (divorces) are observed after losing houses and assets due to cyclones (Kabir et al., 2016). Nonetheless, the affected 
populations are still facing enormous problems due to adverse impacts of climate change because cyclones have increased their vulnerabilities (Kabir et al., 2016). Floods and storms are recurring every year, and as a result, people living in the coastal area have to bear the brunt of climate change.

\section{Comparative Pictures of HFA and SFDRR}

The HFA guided in reducing disaster risk and contributed to achieving Millennium Development Goals (MDGs) and ensuring gender equality. Nonetheless, it did not address the underlying factors of disaster risk. It also failed to chalk out how five priorities for action could be implemented for promoting disaster resilience at the local, regional, national and international levels. Furthermore, this framework did not outline the ways disaster decisionmakers could develop leadership capacities. On the contrary, SFDRR calls for establishing an action-oriented framework guiding state parties and relevant stakeholders in a supportive and complementary manner to identify and reduce disaster risks. This framework offers further opportunities for strengthening disaster management and draws attention to national and international development agencies to invest in promoting resilience (Zia and Wagner, 2015).

The HFA focused mainly on disaster preparedness for the $187 \mathrm{UN}$ member states. However, the Sendai framework aims to raise mass awareness among communities of all sectors of societies to reduce risks and vulnerabilities. It guides to take adequate measures for preparedness. It recommends strengthening the capacities of community leadership so that disaster can be managed effectively and efficiently. As a transformation from HFA to SFDRR, building resilience is a new dimension for disaster-prone communities of the global north and south. At this point, the Sendai Framework has substantially addressed building resilience. Though HFA contributes to MDGs, SFDRR contributes to SDGs. Millennium Development Goals (MDGs) are the predecessor to Sustainable Development Goals (SDGS).

The issues of housing, provisions, social development, employment etc., related to postdisaster relief, rehabilitation and reconstruction offer to rebuild the new patterns of livelihoods and restructure local infrastructure. This opportunity helps the affected community to reduce vulnerability and increase resilience capacity (Kabir et al., 2016). The SFDRR introduces the slogan 'building back better' to promote sustainable infrastructure for the future. Recommendations around how this slogan will be materialized in reality are missed mainly in the framework, but this prioritised area is essential to promote DRR. Strengthening disaster 
resilience may reduce disaster risks, and this will protect individuals, communities, locals and their livelihoods, health, cultural heritage, socioeconomic assets and ecosystems (Kabir et al., 2016).

Both frameworks are explicitly committed to making the substantial reduction of disaster-related losses in lives and economic and environmental assets of communities at local, regional, national and international levels. The integrated aim of these two frameworks is to reduce the substantial disaster risks at the local, national, and regional levels. HFA claimed full involvement of actors: governments, regional and international organisations, civil society members, the private sector and the scientists' communities. The priority of actions are: (i) recognizing the importance and specification of local risk patterns and trends, and decentralizing the responsibilities and resources for disaster risk reduction to relevant subnational or local authorities, as appropriate (Activity i, d, p. 6); (ii) promoting community participation in disaster risk reduction through (a) adoption of specific policies, (b) networking; (c) the strategic management of volunteer resources; (d) the attribution of roles and responsibilities; and (e) the delegation and provision of the necessary authority and resources (Activity iii, h, p.7) (de la Poterie and Baudoin, 2015). In opposition, SFDRR is a more straightforward and time-oriented action policy for implementation, monitoring and reviewing the progress of DRR by involving international, regional, sub-regional and transboundary cooperation including the efforts of states, the national and local authorities, communities and businesses (UNISDR, 2015).

\section{What needs to be learnt}

In order to improve gender equitable resilience for vulnerable people, the Bangladesh Government, together with local NGOs, INGOs, and UN-based organisations, is working relentlessly, and implementing different projects and initiatives, such as a gender and development forum under LGED of the government of Bangladesh, Institutionalizing Gender Equality funded by the ADB (LGED, 2014). The different private and public organisations are working together to materialise the plan of employing more women in policy, practice and decision-making. Local government has taken many initiatives in the coastal area to minimise the vulnerabilities of the disaster. The initiatives include alternative job opportunities, road construction, dam, bridge repairing, ponds digging, and so on. "Kajer Benemoya Khaddo", (work for foods), Vulnerable Group Feeding (VGF), Gratuitous Relief, and Vulnerable Group Development (VGD) programs have been launched to support the affected people. Besides, the 
non-governmental organisations are providing knowledge and training to people to strengthen their capacity to fight environmental hazards and promote the afforestation program (Garai, 2017). According to goals based on gender aspects mentioned in the Sendai Framework, the Bangladesh government is striving to maintain gender dimension, by increasing the ability of people, households and community to adapt and mitigate the impacts of disaster. The government has initiated programmes like Allowance for Widow, Deserted and Destitute, Maternal Health Voucher Scheme, Maternal Allowance Programme for Poor Lactating Mothers to build the capacity of women (Planning Commission 2015). The country is also working to change the existing infrastructure to mitigate anthropogenic disasters. However, women of those communities are still far away from the mainstream, and so their vulnerabilities remain constant (Drolet et al., 2015).

Adequate capacity-building training, workshops on disaster risk reduction and followup at ward, union and Upazila level must be introduced to reduce disaster impacts. Some programmes and initiatives, such as community risk assessment and participatory rural appraisal to identify and assess the vulnerability and hazards, are taken. Activities include planting trees around the houses to protect the cyclonic destruction of their properties, binding tin/thatch house roofs by rope with a pillar to protect its flying in the wind and repairing and raising the embankment/dam to protect entering water into the locality during a disaster (Garai, 2017). Also, disaster relief funding and other aid can be given to women to empower them as well as to ensure gender equality. As most of the time, it is seen that all grants and assistances are given to the male member of the family, and that reinforces gender inequalities in society (Drolet et al. 2015). Climate finance offers aid to countries vulnerable to the impact of climate change. This fund is vital for promoting gender equity (von Meding et al. (2016). Green Climate Fund (GCF) has already accredited to Palli Karma-Sahayak Foundation (PKSF). PKSF has been working to help rural poor people through micro-credit loans. Poor people will benefit through $\mathrm{PKSF}^{4}$.

Reduction of women's vulnerabilities demands special attention of the authority to women. Providing disaster awareness training to women will make them aware of the ensuing hazards. By attending this training, they will be mindful of preserving dry foods during the disaster, protecting their children and elderly members of the family, learn the importance of afforestation and changing diets (Garai, 2017). Shelter houses must have the facilities of water

\footnotetext{
${ }^{4}$ http://pksf-bd.org/portal/web/?p=5493
} 
and sanitation, including separate washrooms and security for women and girls. Besides this, the male member of the family must help ensure the quick evacuation of the house to reach the shelter houses. As most of the poor rural women stay inside, they do not get the warning alert in time, so there must be an alternative way of informing them. von Meding et al. (2016) points out that modern technology (e.g., mobile phone, community radio and public announcement) can help break cultural barriers to get real-time disaster alerts.

Figure 1 listed below shows how women are found to violate the effects of the cultural obstacles hindering their participation in the disaster risk reduction process. It is essential to ensure the rights and justice towards women and opportunities to enhance their empowerment to secure gender equality for all women and girls (SDG 5). Various media and broadcast communication should be accessible for women to be aware of weather updates and disaster signals. Women should also be encouraged to form groups to establish their social cohesion to support their welfare activities. These will help them to improve their livelihood, disaster preparedness, mitigation and prevention actions along with men. They will be also empowered and contribute to the decision-making process in-home and beyond. Ultimately, this will widen their opportunities for increased livelihood and income sources and help them to build resilience.

Figure 1: Women Break the Effects of Cultural Barriers

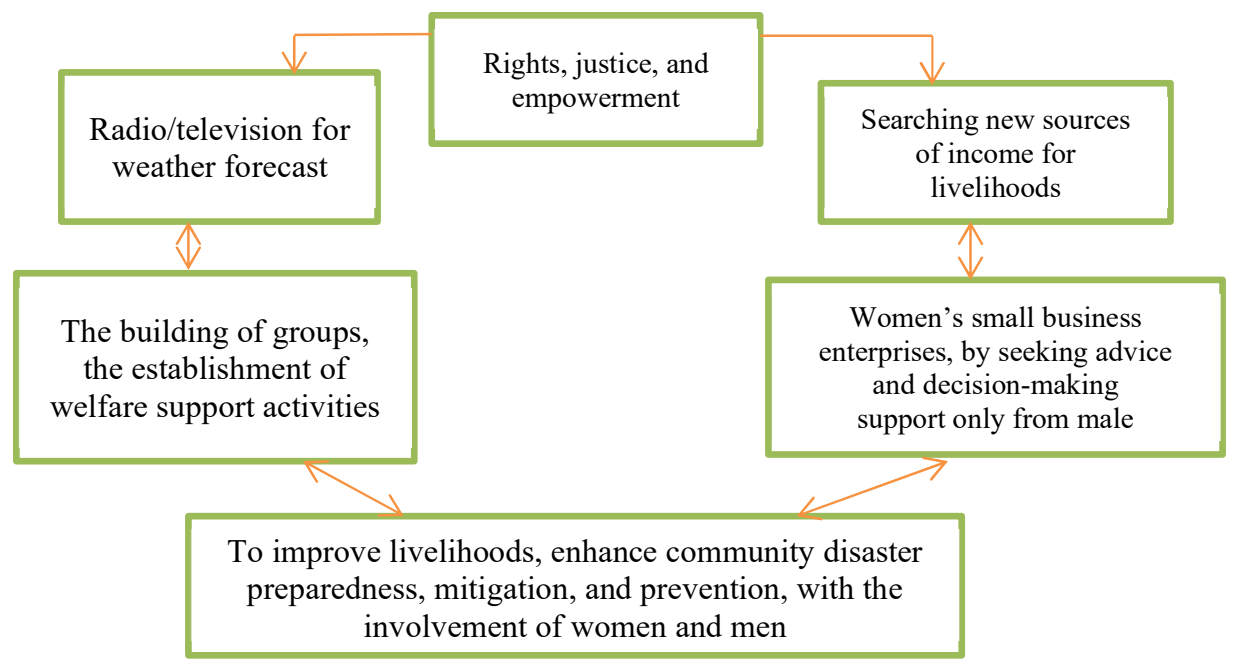

Sources: Garai, 2017; Kabir et. al. 2016 and Drolet et. al, 2015).

To ensure participation of women in disaster risk reduction activities, not only Government and NGOs should come forward, but also the family and society. They have roles 
to ensure women's safety, and thus, women can be prepared for any disaster. If each family allows women to take part in Disaster Risk Reduction activities, women can produce knowledge and gather experiences to contribute to discussions as well as decision-making.

\section{Conclusion}

Reflection to the State-of-Art: HFA and Sendai Framework have made a substantial contribution to Disaster Risk Reduction. On the one hand, Hyogo worked to raise awareness among the people, so that they could reduce disaster risks. On the other hand, the Sendai Framework, adopted later, looks forward to reducing disaster risk of vulnerable countries by increasing involvement of the governments and associate organisations. A greater emphasis on both frameworks has seen impacts on climate change. Different growing scientific evidence reveals that a changing climate is responsible for recurrence of all kinds of natural disasters, and these natural disasters are continuously affecting human lives. Disaster affects both men and women; however, women feel the impact more, and women have to bear the brunt of disasters.

Nevertheless, women can have an immense contribution to mitigation and adaptation. They have their skills and knowledge employed to combat the disaster. Women apply both traditional and modern techniques for Disaster Risk Reduction for survival before, during and post-disaster period. Before the disaster, for example, women help make their house more resilient with existing surrounding resources like strong poles, straw, or enlarging the height of foundation of households and the levels of cowsheds. Women use traditional techniques to protect their livestock. Women also preserve dry foods during hazards, i.e., forest cereals, roots, tubers, rice, onion, garlic, puffed rice, and so on. During a disaster, women do lots of work for their family members so that no harm to them is caused. After the disaster, despite the cultural and social restrictions abided by women and girls, women are required to take on additional roles in the reconstruction of the family as well as the reconstruction of their homes. It increases the female burden of meeting their household responsibilities.

Women must participate and be involved in decision-making processes in a nondiscriminatory manner. Women's knowledge, agency, and collective action should be given full recognition and support to build resilience, reduce disaster risks and contribute to sustainable development. Effective measures should be taken by the Bangladesh government to prevent these vulnerable groups and communities from future catastrophic disasters. 
Stakeholders and policymakers should take the initiative to develop skills and experience to analyse the changing pattern of recent climate change, identify the causes for change and assess the health effects. Therefore, adaptation measures at the community level will help local people to strengthen their barriers against climate-induced disasters. To reduce the vulnerabilities of coastal communities, capacity-building programmes should be taken from household levels to adapt to climate change. This paper discussed and identified the gender dimensions in HFA and SFDRR and showed the implementation of gender norms and gender equality from both the Disaster Risk Reduction and management perspective. It also includes the way men and women combat disaster, its impact on gender and adaptive measures to climate change and underlying hazards.

\section{References}

Alidou, OD 2013, Muslim Women in Postcolonial Kenya, University of Wisconsin Press, Madison.

Ariyabandu, MM 2009, 'Sex, Gender and Gender Relations in Disasters,' in Elaine Enarson and P.G. Dhar Chakrabarti (eds), Women, Gender and Disaster, Global issues and Initiatives, Sage Publication, pp. 5-17.

Childs, D 2013, Implementation of Hyogo Framework of actions, United Nations Office for Disaster Risk Reduction (UNISDR), Geneva, Switzerland.

de la Poterie, AT \& Baudoin, MA 2015, 'From Yokohama to Sendai: Approaches to participation in international disaster risk reduction frameworks', International Journal of Disaster Risk Science, Vol. 6, No. 2, pp. 128-139.

Drolet, J, Dominelli, L, Alston, M, Ersing, R, Mathbor, G \& Wu, H 2015, 'Women rebuilding lives post-disaster: innovative community practices for building resilience and promoting sustainable development', Gender \& Development, Vol. 23, No. 3, pp. 433-448.

Garai, J 2017, 'Qualitative analysis of coping strategies of cyclone disaster in coastal area of Bangladesh', Natural Hazards, Vol. 85, No. 1, pp. 425-435.

Ginige, K, Amaratunga, D \& Haigh, R 2009, 'Mainstreaming gender in disaster reduction: why and how?', Disaster Prevention and Management, Vol. 18, No. 1, pp. 23-34.

Glantz, MH \& Baudoin, MA 2014, Working with a Changing Climate, Not Against It: Hydro-Meteorological Disaster Risk Reduction; A Survey of Lessons Learned for 
Resilient Adaptation to a Changing Climate, Consortium for Capacity Building, University of Colorado, Boulder.

Islam, MR 2012, 'Vulnerability and coping strategies of women in disaster: a study on coastal areas of Bangladesh', Arts Faculty Journal, Vol. 4, pp. 147-169.

Kabir, R, Khan, HTA, Ball, E \& Caldwell, K 2016, 'Climate Change Impact: The Experience of the Coastal Areas of Bangladesh Affected by Cyclones Sidr and Aila,' Journal of Environmental and Public Health, Vol. 2016, pp. 9.

Ki-moon, MB 2016, Prevention Web. Accessed 21 November 2016. https://www.preventionweb.net/drr-framework/sdg

Kuruppu, N \& Willie, R 2015, 'Barriers to reducing climate enhanced disaster risks in Least Developed Country-Small Islands through anticipatory adaptation', Weather and Climate Extremes, Vol. 7, pp. 72-83.

LGED, 2014, Gender equality and strategy, Local Government Enginering Department, the People's Republic of Bangladesh, Accessed June 6, 2021 from http://oldweb.lged.gov.bd/UploadedDocument/Gender/Publication/GenEquStraEnglis h-2014.pdf

Lisa, E, Schipper, F, Thomalla, F, Vulturius, G, Davis, M \& Johnson, K 2016, 'Linking disaster risk reduction, climate change and development', International Journal of Disaster Resilience in the Built Environment, Vol. 7, pp. 216-228.

Mallick, B, Ahmed, B \& Vogt, J 2017, 'Living with the Risks of Cyclone Disasters in the South-Western Coastal Region of Bangladesh', Environments, Vol. 4, pp. 15.

Moller, AM \& Myles, PS 2016, 'What makes a good systematic review and metaanalysis?', British Journal of Anaesthesia, Vol. 117, No. 4, pp. 428-430.

Planning Commission, 2015, National Social Security Strategy (NSSS) of Bangladesh, Dhaka, General Economics Division (GED), Ministry of Planning.

Prevention Web, 2017. UNISDR Prevention Web, Accessed June 10, 2021 from http://preventionweb.net/go/51762

Rezwana N \& Pain R 2020, Gender-based violence before, during and after cyclones: slow violence and layered disasters. Disasters.

Saha, SK \& James, H 2017, 'Reasons for non-compliance with cyclone evacuation orders in Bangladesh' International Journal of Disaster Risk Reduction, Vol. 21, pp.196-204.

Samira, S 2013, Recovery of Household-Level Assets: Towards a Cyclone Resilient Community, BRAC University, Dhaka. 
Smith, V, Devane, D, Begley, CM, \& Clarke, M 2011, 'Methodology in conducting a systematic review of systematic reviews of healthcare interventions', BMC Medical Research Methodology, Vol. 11, No. 15, pp. 1-6.

UNISDR, 2003, United Nations documents related to disaster reduction 2000-2002, The United Nations Office for Disaster Risk Reduction, Geneva, Switzerland.

UNISDR, 2014, Progress and Challenges in Disaster Risk Reduction: A contribution towards the development of policy indicators for the Post 2015 Framework on Disaster Risk Reduction, The United Nations Office for Disaster Risk Reduction, Geneva, Switzerland.

UNISDR, 2015, Sendai framework for disaster risk reduction 2015-2030. The United Nations Office for Disaster Risk Reduction, Geneva, Switzerland.

von Meding, J, Wong, J, Kanjanabootra, S \& Tafti, MT 2016, 'Competence-based system development for post-disaster project management' Disaster Prevention and Management, Vol. 25, No. 3, pp. 375-394.

Wahlström, M 2012, Japan's resilience lessons, Accessed June 6, 2021 from http://www.project-syndicate.org/commentary/japan-s-resilience-lessons

WHO, 2013, Considering gender norms, roles and relations in institutional processes, Accessed May 20, 2021 from https://www.who.int/gender/mainstreaming/GMH_Participant_ConsideringGenderNo rms.pdf

Zia, A \& Wagner, CH 2015, 'Mainstreaming early warning systems in development and planning processes: Multilevel implementation of Sendai framework in Indus and Sahel’ International Journal of Disaster Risk Science, Vol.6, No. 2, pp. 189-199. 